\title{
Review:
}

\section{Electrogenerated Chemiluminescence for Immunoassay Applications}

\author{
Isnaini Rahmawati ${ }^{1}$, Irkham Irkham ${ }^{2}$, Rahmat Wibowo ${ }^{1}$, Jarnuzi Gunlazuardi ${ }^{1}$, \\ Yasuaki Einaga ${ }^{2}$, and Tribidasari Anggraningrum Ivandini ${ }^{{ }^{*}}$
}

${ }^{1}$ Department of Chemistry, Faculty of Mathematics and Natural Sciences, Universitas Indonesia, Kampus UI, Depok 16424, Indonesia

${ }^{2}$ Department of Chemistry, Faculty of Science and Technology, Keio University, Hiyoshi 3-14-1, Yokohama, 223-8522, Japan

\begin{abstract}
${ }^{*}$ Corresponding author:
tel: $+62-21-7270027$

email:ivandini.tri@sci.ui.ac.id

Received: March 9, 2021

Accepted: June 17, 2021

DOI: $10.22146 /$ ijc. 64596

Abstract: Electrogenerated chemiluminescence (ECL) has recently become one of the most prominent and well-established transducers for immunoassay techniques. ECL relates a luminophore concentration in solution with the emission of light triggered by an electrochemical stimulus. ECL immunoassay (ECLIA) performance depends on the parameters of its light generation, including the luminophore, the species that emit light called labels in ECLIA; co-reactants, which are added reagents that support the luminophore to undergo the excited state; electrodes, which are the place for the ECL reactions to take place; and the format of the immunoassay. This review discusses the behaviour of ECLIA parameters, the required instrumentations, and some important examples of detections based on ECLIA.
\end{abstract}

Keywords: antibody; antigen; electrochemiluminescence; ECL; ECLIA; immunoassay

\section{- INTRODUCTION}

Electrogenerated chemiluminescence, also called electrochemiluminescence (ECL), is a luminescence produced by the transfer of high-energy electrons on the electrode surface due to the relaxation of the excited state [1-2]. The first observations of light emission during electrolysis were published in the 1920s, but Bard and Hercules' first ECL experiments were carried out in the mid-sixties [3]. After the introduction by Bard, ECL continues to be developed as an effective analytical technique, mainly having importance in biological targets [2,4-5].

As a bioanalytical technique, ECL combines the sensitivity of luminescence with the low cost of electrochemistry. This combination offers many potential benefits $[2-3,6]$. The electrochemistry property allows ECL to control the position and the time of the emission, which can increase the sensitivity, selectivity, reproducibility, and often simplify the operation of ECL [3,7]. Since current and light signals are obtained simultaneously, it is possible to monitor the electrochemical reaction and ECL detection at the same time [3].

On the other hand, immunoassay is a widespread technique in bioanalytical applications for diagnosing diseases, drug monitoring, food testing, and environmental monitoring [8]. Immunoassays allow a specific detection with the selective interaction between antigen and antibody in complex biological samples. Initially, the transducers employed for immunoassays were based on radioimmunoassay (RIA) and enzymelinked immunosorbent assay (ELISA), which became essential analytical tools ever since [7-8]. However, nowadays, electrochemiluminescence immunoassay (ECLIA) has become a better option for immunoassay as it can overcome the limitation of RIA and ELISA, such as the use of radioisotope in RIA and the use of enzyme for ELISA that has limited stability due to easy denaturation and treatment under special conditions [7].

Furthermore, good sensitivity and selectivity must be possessed to develop a promising biosensor. Various parameters are affecting the performance of ECLIA- 
based biosensors. The label of ECLIA, co-reactant, and electrode that have been used in the system are essential parameters to gain high ECL intensity [6-7]. In this resume, we briefly summarized the label, co-reactant, and electrode as the parameters of ECLIA. In addition to that, ECL instrumentation and some applications for various analyte detections with ECLIA systems are also highlighted.

\section{- BASIC THEORY OF ECLIA}

ECL is a particular form of chemiluminescence in which light emissions are induced by electrochemical reactions $[2,5]$. The principle of light emission in the ECL is described in Fig. 1. First, through the transfer of heterogeneous electrons on the electrode, an electrogenerating species, usually a radical ion, is formed. Second, the generation of excited states by interacting with precursors ions through homogeneous electron transfer reaction [3]. The signal of ECL can be detected when the electrons in the excited state return to the ground state. Photon emission is identified in a particular wavelength controlled by the energy gap between those two states [2-3].

Traditionally, ECL was generated via the annihilation pathway. In annihilation, applying pulsed potentials at the electrode resulted in the reduced $\mathrm{A} \bullet^{-}$and oxidized $\mathrm{D}^{+}{ }^{+}$species. These two intermediates diffuse, and the recombination between $\mathrm{A}_{\bullet}^{-}$and $\mathrm{D}_{\bullet}{ }^{+}$occurs to generate the excited state $A^{*}$ (Fig. 2) [1-2,9]. It is important to note that $\mathrm{A}$ and $\mathrm{D}$ can be the same initial molecule, and only the redox states are different [9]. The annihilation pathway involves high reactive intermediates and usually needs pure aprotic solvents and deoxygenated solution conditions $[6,10]$.

In the '80s, a new approach for generating ECL was presented for the first time and it was called the coreactant pathway [10]. Luminophore generates an excited state supported by an added reagent called co-reactant in their reactive intermediate. The potential is swept in one direction (Fig. 3) [2,5,9]. The co-reactant can be selected among various chemicals. To select a potent co-reactant to produce optimum ECL intensity in ECL co-reactant systems, the co-reactant must have solubility in the considered medium, low reduction or oxidation potentials depending on the mechanistic pathways, stability, kinetics, quenching effects, toxicity, sufficient redox potentials, and radicals' lifetime [9]. Two types of co-reactant are based on their corresponding mechanisms, referred to as 'oxidative-reduction' and 'reductive-oxidation' ECL, [2] that will be discussed further.

This co-reactant pathway is an important point of ECL in analytical applications because it is different from the annihilation pathway. Co-reactant is suitable for water environments, required by all bio-related samples

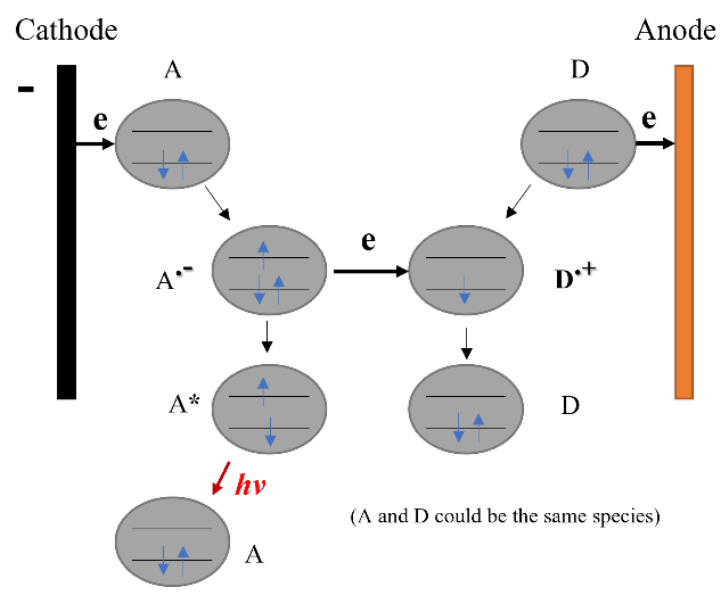

Fig 1. The principle of light emission in the ECL scheme. $A$ and $D$ are reactants; $A$ and $D$ may be the same species. A - = highly reduced $\mathrm{A}, \mathrm{D}^{+}{ }^{+}=$highly oxidized $\mathrm{D}, \mathrm{A}^{*}=$ $A$ at the excited state. Adapted with permission from (Chem. Rev., 2008, 108 (7), 2506-2553), Copyright (2008) American Chemical Society [2]

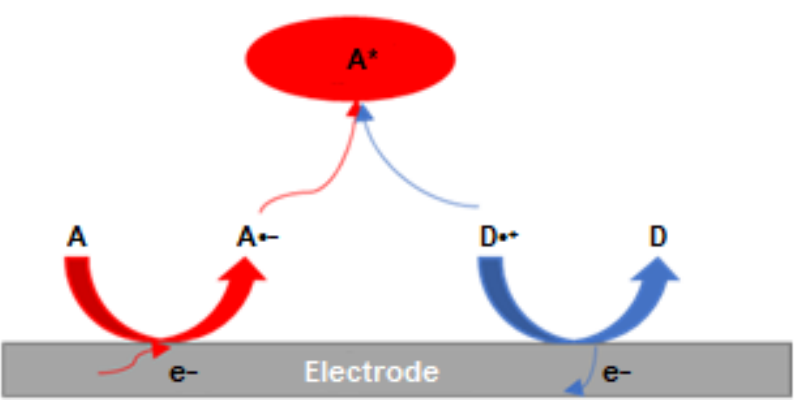

Fig 2. The principle of light emission in the ECL annihilation pathway. A and D are reactants; A and D are the same species. $\mathrm{A}_{\bullet^{-}}=$highly reduced $\mathrm{A}, \mathrm{D}^{+}=$ highly oxidized $\mathrm{D}, \mathrm{A}^{*}=\mathrm{A}$ at the excited state. Adapted with permission from (Chem. Rev., 2008, 108 (7), 25062553), Copyright (2008) American Chemical Society [2] 


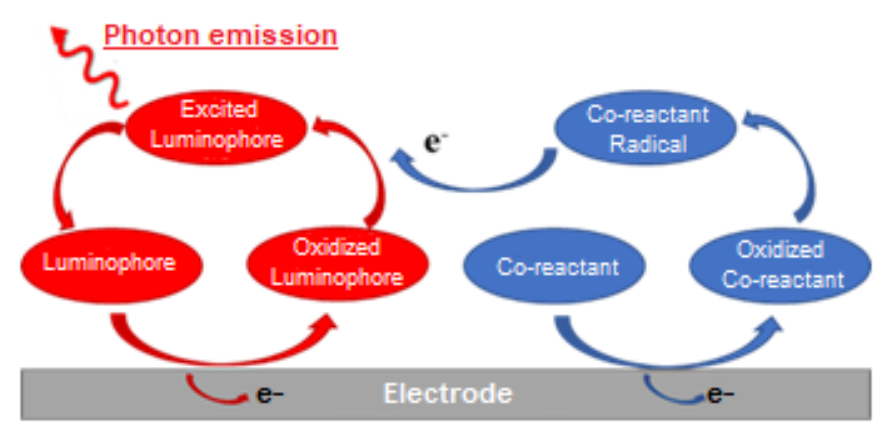

Fig 3. The principle of light emission in the ECL coreactant pathway. Using two reactants, luminophore, and co-reactant. Adapted with permission from (Chem. Rev., 2008, 108 (7), 2506-2553), Copyright (2008) American Chemical Society [2]

or analytes [2,7]. Co-reactant-based ECL is a well-known analytical technique because it has high selectivity and sensitivity due to luminescence and electrochemical properties. ECL technique combines spectroscopic and electrochemical methods $[6,10]$. Due to their electrochemical properties, ECL also has some advantages where even in a complex matrix, it can control time and position of transduction under low background and high sensitivity [10].

ECL has a multiplied selectivity in the field of biosensors due to its nature and biosensors' qualification. ECL must be electroactive to experience a redox reaction, and it must also be participating in a chemiluminescent reaction. Furthermore, the selectivity of the biosensor is specific to biological interactions. As for immunoassay, it is based on the interaction between antibody and antigen [6].

ECLIA has specific characteristics compared to other immunoassays, i.e., ECLIA does not use any radioisotope, so it is better for the environment. ECLIA has a lower background because there is no optical excitation from the scattered light source or sample autofluorescence. The ECLIA label has quite a low detection limit because some of the labels, such as ruthenium complex, can be regenerated on the electrode surface, thus providing excellent sensitivity for detecting analytes at very low concentrations. The measurement of ECLIA only takes a few seconds, even milliseconds, because fluorescence is a rapid process. Multiparameter analyses of ECLIA are feasible because the signal can be

obtained using ECL intensity, peak voltages or ECL onset, and wavelength [3,7].

The ECL reactions must occur to fabricate a sensitive and selective biosensor based on immunoassay and the proper order of interaction of the antibody and antigen. A variety of formats have been established, each with its terminology and characteristics. Many of these formats improve the selectivity and sensitivity and develop the miniaturized devices [6]. The following are the fundamental interactions that occur in the ECLIA.

\section{Direct Interaction}

The formats of direct interactions are described in Fig. 4(a). In this interaction, there is only one antibody used in the system. The electrode is usually modified with species that serves both capture and ECL probe. These species are defined as species that can recognize the analyte and be labeled with the luminophore. When the electrode is placed in a solution of co-reactant and the electrode is appropriately biased, a strong ECL signal will be observed. If an analyte ( $\mathrm{Ag})$ exists in the solution, the analyte binds to the Ab labelled with ECL, and then the ECL signal will decrease. Generally, the decrease of the ECL signal is proportional to the concentration of the analyte $[6,11]$.

\section{Competitive Interaction}

In the competitive interaction, the system includes antibodies and an analog of antigen labelled with luminophore. The antibody is modified on the electrode surface (Fig. 4(b)). In the presence of Ag, the analyte competes with the analogue for binding to the antibody

(a)

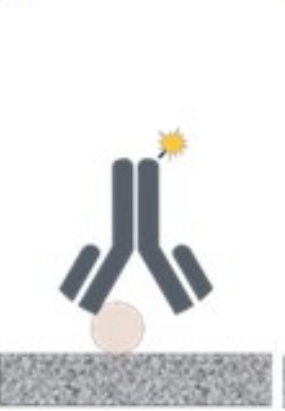

Fig 4. ECLIA format: a) direct ECLIA, b) competitive ECLIA, c) sandwich ECLIA 
so the concentration of labels in the system will decrease. Generally, the concentration of the analyte will be inversely proportional to the ECL signal [7].

\section{Sandwich Interaction}

Fig. 4(c) shows the format of the sandwich interaction. In the sandwich interaction, two different antibodies are needed. The primary antibody (Ab1) is usually immobilized on the electrode surface as a capture probe. The secondary antibody (Ab2) is labelled with luminophore known as ECL probes. In the presence of the target antigen, the antigen is bound to form an immunocomplex with a capture probe and ECL probe. The ECL intensity is proportional to the concentration of the target antigen [6].

Besides these three interactions, the label-free method has been widely used in ECLIA [12-21]. In labelfree ECLIA, luminophore is not labelled in the antibody but is present in the system as an added reagent. The concentration of the analyte can be directly or inversely proportional to the ECL signal, depending on the immunocomplex synthesized in the system.

\section{- LABEL FOR ECLIA}

The labels for ECLIA are chemical compounds that can be conjugated with an antibody or antigen. In ECLIA, the labels are the species that emit light, called luminophores. Most of the reported luminophores for ECL have low water solubility and encounter obstacles when introducing binding sites without affecting their functions and properties [5]. This limits luminophores as a possible candidate to be used as labels in ECLIA. So far, $\left[\mathrm{Ru}(\mathrm{bpy})_{3}\right]^{2+}$ are practically the only luminophore employed in the commercial ECLIA [2,7]. Luminophores could be classified into three categories, namely inorganic and organic systems as well as nanomaterials. The inorganic system mainly uses organometallic complexes as the materials [2]. This section discusses the luminophores that have been reported as labels in ECLIA.

\section{Inorganic System}

\section{$\left[R u(b p y)_{3}\right]^{2+}$ and its derivatives}

Due to their outstanding properties in luminescent and electrochemistry, $\left[\mathrm{Ru}(\mathrm{bpy})_{3}\right]^{2+}$ and its derivates are widely studied for ECL luminophore [2,22-23]. The first study of $\left[\mathrm{Ru}(\text { bpy })_{3}\right]^{2+}$ as a luminophore for ECL was via the annihilation process in acetonitrile solution with tetra- $n$-butylammonium tetrafluoroborate $\left(\mathrm{TBABF}_{4}\right)$ as the electrolyte using Pt electrode [23]. Furthermore, trin-propylamine (TPrA) [24], 2-(dibutylamino)ethanol (DBAE) [25], persulfate $\left(\mathrm{S}_{2} \mathrm{O}_{8}{ }^{2-}\right)$ [26], hydrogen peroxide $\left(\mathrm{H}_{2} \mathrm{O}_{2}\right)$ [27], and benzoyl peroxide (BPO) [28] were also applied for ECL generation with $\left[\mathrm{Ru}(\mathrm{bpy})_{3}\right]^{2+}$ and its derivates. Among these various co-reactants, TPrA has become the most studied co-reactant for $\left[\mathrm{Ru}(\mathrm{bpy})_{3}\right]^{2+}$. Furthermore, $\left[\mathrm{Ru}(\mathrm{bpy})_{3}\right]^{2+} / \mathrm{TPrA}$ is so far the only commercially available ECL and ECLIA system [2,21]. Most of the ruthenium complexes have maximum wavelengths at $600-650 \mathrm{~nm}$. However, it was also reported that some acrylate-containing $\left[\mathrm{Ru}(\mathrm{bpy})_{3}\right]^{2+}$ complexes have maximum wavelengths at $640-700 \mathrm{~nm}$ [22].

Being the most used luminophore, $\left[\mathrm{Ru}(\mathrm{bpy})_{3}\right]^{2+}$ and its derivates have also become the most popular label in ECLIA and can detect many biological matrices with good sensitivity. $\left[\mathrm{Ru}(\mathrm{bpy})_{3}\right]^{2+}$ has been the most used label because (a) this label can undergo ECL reactions in an aqueous buffer medium, which is perfect for biological matrices, (b) it is not disturbed by oxygen so degassing to remove the dissolved oxygen is not necessary, (c) fully reversible one-electron transfer so the emission of light will be optimum, (d) $\left[\mathrm{Ru}(\mathrm{bpy})_{3}\right]^{2+}$ can be adequately linked to antibody, antigen, or biological samples with various bioconjugates strategies $[7,21]$.

Many studies aim to design a ruthenium complex with more ECL efficiency, better than the standard $\left[\mathrm{Ru}(\mathrm{bpy})_{3}\right]^{2+}$ or to modify the ruthenium complex so it can be used for analytical applications prospects [2,22,30-32]. This can be achieved by two strategies, including the bpy ligand functionalization or other ligands replacement to obtain another homogeneous or heteroligated complex. The energy of the excited state and the relative energy of HOMO and LUMO are changed. If the energy for the excited state (bandgap HOMO-LUMO) is higher than the energy available in the electron transfer between complex and co-reactant, there will be no emissions. Meanwhile, if the energy is barely sufficient, it might generate low emissions. For 
energy larger than HOMO-LUMO, there will be emissions. In addition, the ligands affect the photoluminescence and consequently the ECL.

The $\left[\mathrm{Ru}(\mathrm{bpy})_{3}\right]^{2+} / \mathrm{TPrA}$ system is the first system for commercial ECLIA and generates the highest efficiency of ECL $[2,5]$. As a label in ECLIA, usually, the ruthenium complex is immobilized in a solid phase such as a nanoparticle, and then it conjugates with the antibody to become ECL probes. Nevertheless, for the label-free ECLIA, the ruthenium complex usually presents an added reagent in the immunosensor.

\section{Cyclometalated iridium(III) complexes}

In the early 2000s, cyclometalated Ir(III) complexes were studied as new luminophores for ECL [33-36]. Ir(III) complexes have similar electrochemical and spectroscopic properties to $\left[\mathrm{Ru}(\mathrm{bpy})_{3}\right]^{2+}$ and have maximum wavelengths around 600-615 nm [22]. $\operatorname{Ir}(\mathrm{III})$ complexes can undergo the ECL behavior with both annihilation and co-reactant pathways [22] via oxidative reduction (TPrA) [36] or reductive oxidation $\left(\mathrm{S}_{2} \mathrm{O}_{8}{ }^{2-}\right)$ [37] and have higher ECL efficiencies and ECL intensity compared to $\left[\mathrm{Ru}(\mathrm{bpy})_{3}\right]^{2+}[22-23,30]$.

Ir(III) complexes have also become luminophores that have been widely studied because Ir(III) complexes have higher quantum yields to enhance the analytical performances. The change of their ligand can affect the emission wavelengths and electrochemical potentials so that it can be easily manipulated according to the needs, and this enables multi-color and potential resolving multiplexed ECL systems [21,29].

Nevertheless, despite their superiority, $\operatorname{Ir}(\mathrm{III})$ complexes have not been used effectively as ECL labels for any biosensors or ECLIA because of some limitations. The (a) Ir(III) complexes have less water solubility than $\left[\mathrm{Ru}(\mathrm{bpy})_{3}\right]^{2+}$, so for immunoassay that needs an aqueous solution, these complexes are not compatible. (b) Only a small amount of ligands of $\operatorname{Ir}(\mathrm{III})$ complexes and their derivates have functional groups suitable for bioconjugation with antibodies, antigens, or any biological samples. Therefore, $\operatorname{Ir}(\mathrm{III})$ complexes are hardly used as labels compared to the $\mathrm{Ru}$ complexes $[21,29,38]$.

\section{Other metal complexes}

Many others metal complexes were also studied as ECL luminophores [21]. These central metal ions include $\mathrm{Os}(\mathrm{II})$ [39], $\mathrm{Tb}$ (III) [41-42], Eu(III) [43-44], $\mathrm{Pt}(\mathrm{II})$ [44], Mo, or their combinations such as Os(II)$\mathrm{Ru}(\mathrm{II})$ and $\mathrm{Os}(\mathrm{II})-\mathrm{Ir}$ (III) [21]. However, Ru and Ir are the most frequently used because they have the highest ECL emission efficiency, while others have lower efficiencies. Other metal complexes have limitations; (a) the photoluminescence emission efficiencies are lower compared to $\mathrm{Ru}$ and $\mathrm{Ir}$, (b) the energy in the electron transfer is not enough or is barely sufficient to bring the complex to the excited state, and (c) the complex is not stable after reduction or oxidation that leads to a breakup. Moreover, while Ir is sometimes more efficient than $\mathrm{Ru}$, usually such complexes are more expensive and less water soluble, which is why $\mathrm{Ru}$ is still the best choice for ECL or ECLIA applications.

\section{Organic Systems}

\section{Polycyclic aromatic hydrocarbons (PAHs)}

ECL luminophores from organic materials include 9,10-diphenylanthracene (DPA) and rubrene with high ECL intensities that can be excellent candidates for ECL labels [2,5]. However, their poor water solubility and radical instability in aqueous media and the lack of functional groups for bioconjugation have limited the PAHs' applications in ECLIA [2,21]. Early studies suggest the introduction of sulfonate, carbonate, or carboxylate groups to the structures of DPA and rubrene in order to make them more soluble. A recent method used nanotechnology and emulsion modification to produce ECL in various water-soluble PAHs luminophores [46-48].

Rubrene is used as a label in ECLIA specifically to detect the Zika virus by overcoming the water-soluble limitations. For easy separation, rubrene is loaded in polystyrene beads and coated with avidin as a linker to the antibody via avidin-biotin interaction [28]. This immunosensor has a detection limit down to $1 \mathrm{PFU}$ for the Zika virus [28]. DPA was modified into a DPA nano block with polyvinyl alcohol as a protectant to have good dispersibility and stability sensors [46]. The DPA nano 
block biosensor has a detection limit of up to $29.5 \mathrm{aM}$ for the detection of miRNA-141.

\section{Luminol}

Another popular luminophore and ECL label besides $\left[\mathrm{Ru}(\mathrm{bpy})_{3}\right]^{2+}$ is luminol (5-amino-2,3-dihydro1,4-phthalazinedione) [2,5]. The main issue of organic luminophores is solubility. Luminol, with better solubility properties in water compared to other organic luminophores, becomes the most frequently used organic ECL luminophore and labels system. Organic luminophores besides luminol require more energy than $\mathrm{Ru}$ or Ir (blue emission), which means low ECL efficiency with co-reactants. They can be used almost exclusively for annihilation in organic solvents.

Luminol is often produced in alkaline solution via a co-reactant pathway with hydrogen peroxide or other reactive oxygen species (ROS) as the co-reactant $[2,49$ 50]. Emission of ECL results from the excited state in 3-aminophtalate, which has maximum wavelengths at $420 \mathrm{~nm}[34,48]$. Luminol has the most efficient ECL reaction under alkaline conditions [2,50]. Many studies aim to broaden the $\mathrm{pH}$ range, and for analytical purposes, luminol can be used in neutral and even weakly acidic conditions $[49,51]$.

For ECLIA applications, luminol is usually loaded on solid surfaces or becomes an added reagent if the type of immunosensor is label-free. The detection of $a-1$ fetoprotein (AFP), carcinoembryonic antigen (CEA), and transferrin are examples of using luminol as the labels $[15,49,52]$. All works mentioned earlier on luminol as a label for ECL immunoassay have also been studied for the specific immune recognition and high sensitivity of ECL luminol with the help of various nanomaterials to achieve an excellent performance.

\section{Nanomaterials}

Most of the reported ECL luminophores, which are molecular labels, have several limitations, such as their limited photostability and problems in binding with biological samples without affecting their functionality [7,53]. Nanomaterials, particularly semiconductor nanoparticles and quantum dots, are promoted as novel luminophores to overcome this limitation. At first, an
ECL system using nanomaterials was reported in 2002, which used silicon nanocrystals as a luminophore [54]. Since then, the study of nanomaterials as luminophores or labels became popular.

Nanomaterials usually undergo co-reactant pathways, both oxidative reduction (using TPrA, DBAE, oxalate) and reductive oxidation (using hydrogen peroxide and peroxydisulfate) [2,7]. Both of the QDs or semiconductor $\mathrm{Np}$ can be used in direct, sandwich, competitive, or label-free types of immunoassay by quenching, inhibiting, or enhancing the ECL intensity, depending on the system and purpose of study [7].

Other than becoming a new luminophore and label, nanomaterials have also promoted highperformance ECLIA because it also acts as a platform for loading a large number of ECL labels such as ruthenium or luminol. The nanomaterial can be in the form of nanoparticles, porous noble metals as label loaders; dendrimers, liposome as label encapsulators; and composites as immobilization support [7]. Nanomaterials can also become an electrocatalyst in certain reactions to increase the electron transfer and electrocatalytic activities [7,53].

Sun et al. [14] studied the use of Zinc Cadmium Sulfide/Zinc Sulfide quantum dots (ZnCdS@ZnS QDs) as a label in the detection of aflatoxin $\mathrm{B}_{1}$. ZnCdS QDs capped with $\mathrm{ZnS}$ and assembled with Nafionimmobilized Au electrode. The label is coupled with anti-AFB1 antibodies as the sensing agent. The intensity of ECL decreases with the increasing detected concentration of AFB1. This immunosensor can detect AFB1 with LOD until $0.01 \mathrm{ng} / \mathrm{mL}$ in a wide concentration range of $0.05-100 \mathrm{ng} / \mathrm{mL}$.

\section{Strategies of Bioconjugation}

As an ECLIA label, a luminophore must be conjugated with biological samples such as an antigen or an antibody. It is necessary to have strategies to bioconjugate the luminophore with the biological samples, usually by using linking groups that are suitable for biological samples. There are various linking groups that are suitable for ruthenium complexes derivates to conjugate with biological samples, such as using 
phosphoramidite for conjugation with oligonucleotides, NHS ester for linking with amines on protein, hydrazide for carbohydrate ruthenium complexes, and using amines as linking groups for reactions with carboxylic acids on proteins, or maleimide for thiols [21]. The choice of linking groups depends on the purpose of the research.

For coupling with antigens or antibodies, such as interactions of biotin-streptavidin (SA), modification on the nanomaterials' surface is normally conducted. However, other linking groups in nanomaterials that could be modified to provide a coupling with biological samples are also available. Some of them are coordination compounds with thiols, imidazole/histidine, or ligand/hydrophobic interactions and coatings with amine or carboxyl to enable interaction with amine from biomolecules. In addition, coating with functionalized PEG, electrostatic association, and nickel mediated assembly of poly-histidine as well as activation and coupling of maleimide or active esters were also reported $[7,55]$.

\section{- ECL CO-REACTANT}

Applications of ECL, especially ECLIA, use coreactant pathways because it is suitable for an aqueous environment which is the perfect ambiance for biomolecules. Unlike the annihilation pathway, in a coreactant pathway, the solution contains luminophores and an added reagent, which upon oxidation or reduction, can generate a highly reactive intermediate to provide reactions with luminophores, forming an excited state to emit light $[2,5,56]$.

Straightforwardly, there are four steps for luminophores to emit light via the co-reactant pathway [56]. First, the luminophore and co-reactant will form a radical when potential is applied on the electrode. Second, the co-reactant in the form of radicals decomposes and generates highly reducing or oxidizing species. Next, those high reducing or oxidizing species react with the luminophore to generate an excited state from the luminophore. Last, the excited luminophore goes back to the ground state while emitting light.

Based on the mechanism of co-reactants, they can be divided into two classes: (a) Oxidative-reduction co- reactants, where the electrooxidation of a co-reactant generates highly reducing intermediate species. For example, oxalate ion $\left(\mathrm{C}_{2} \mathrm{O}_{4}{ }^{2-}\right), \quad \mathrm{TPrA}$, and 2(dibutylamino)ethanol (DBAE); and (b) Reductiveoxidation co-reactants where electroreduction of a coreactant generates highly reducing intermediate species. For example, peroxydisulfate and $\mathrm{H}_{2} \mathrm{O}_{2}$ [2,9]. In this section, the reaction mechanism of some popular coreactants is explained with ruthenium complexes as a model of luminophore.

\section{Oxidative Reduction Co-reactants}

\section{Oxalate $\left(\mathrm{C}_{2} \mathrm{O}_{4}{ }^{2-}\right)$}

Oxalate was the first discovered co-reactant with $\left[\mathrm{Ru}(\mathrm{bpy})_{3}\right]^{2+}$ as a luminophore in an acetonitrile medium as well as in an aqueous medium using a platinum electrode, that eventually became a classic example of the oxidative-reduction system [2,57-58]. In an aqueous medium, upon the positive potential scanning, $\left[\mathrm{Ru}(\mathrm{bpy})_{3}\right]^{2+}$ is oxidized first to become $\left[\mathrm{Ru}(\mathrm{bpy})_{3}\right]^{3+}$, then oxalate is oxidized by $\left[\mathrm{Ru}(\mathrm{bpy})_{3}\right]^{3+}$ to form an oxalate radical anion. The radical decomposes to produce $\mathrm{CO}_{2}$ and a highly reductive radical anion. The excited state can be formed when the highly radical anion reacts with $\left[\mathrm{Ru}(\mathrm{bpy})_{3}\right]^{3+}$ and when the reaction between $\left[\mathrm{Ru}(\mathrm{bpy})_{3}\right]^{+}$, the form of the reduced $\left[\mathrm{Ru}(\mathrm{bpy})_{3}\right]^{2+}$, with $\left[\mathrm{Ru}(\mathrm{bpy})_{3}\right]^{3+}$ occur. The light emission of this system occurs at maximum wavelengths of $620 \mathrm{~nm}$. In a non-aqueous system, oxalate will be oxidized first because it is easier to oxidize than $\left[\mathrm{Ru}(\mathrm{bpy})_{3}\right]^{2+}[56]$.

\section{Tri-n-propylamine (TPrA)}

The use of TPrA as a co-reactant started when Bard et al. [27] discovered the high efficiency of ECL of $\left[\mathrm{Ru}(\mathrm{bpy})_{3}\right]^{2+}$ in the presence of an aliphatic amine. It was found that TPrA is an efficient co-reactant $[2,56]$. After that, the $\left[\mathrm{Ru}(\mathrm{bpy})_{3}\right]^{2+} / \mathrm{TPr} \mathrm{A}$ system was studied and became a system for bio applications like ECLIA. This system was the only commercial ECLIA at the time.

The ECL mechanism of $\left[\mathrm{Ru}(\mathrm{bpy})_{3}\right]^{2+} / \mathrm{TPr} \mathrm{A}$ was complicated. Miao reported that the ECL of this system has two peaks as a function of the applied potential. The first peak is an analog to the direct oxidation of TPrA on 
the electrode surface, and the second peak is the oxidation wave of $\left[\mathrm{Ru}(\mathrm{bpy})_{3}\right]^{2+}$. TPrA is oxidized on the electrode surface to generate a strong reducing species, radical TPrA, which will later react with electrogenerated $\left[\mathrm{Ru}(\mathrm{bpy})_{3}\right]^{3+}$ to produce $\left[\mathrm{Ru}(\mathrm{bpy})_{3}\right]^{2+}$ in an excited state that can emit light while going back to the ground state. Alternatively, the strong reducing species, radical TPrA, can also be obtained by the reaction of TPrA with $\left[\mathrm{Ru}(\mathrm{bpy})_{3}\right]^{3+}[2,21,24]$.

\section{2-(Dibutyl amino)ethanol (DBAE)}

Although TPrA is the most popular co-reactant, it is well known that TPrA is toxic, volatile, and has a low electrochemical oxidation rate [24,27]. It was reported that DBAE could be applied as an alternative for environmentally friendly applications. With the same system, Au and Pt electrodes using DBAE as a co-reactant produces $100 \mathrm{x}$ higher ECL intensity compared to TPrA [25,56]. This might be because of the molecular structure of the co-reactant that affects the ECL intensity. In $\mathrm{Ru} /$ amine systems, the ECL emission is mainly due to the rate of deprotonation. Faster rates give higher ECL, and it goes in the order of tertiary $>$ secondary $>$ primary amines or electron-withdrawing group in DBAE. The other reason is possibly due to the energy and the stability of radicals. Energy is available in the electron transfer between $\mathrm{Ru}$ and the amine radical; higher energy gives higher ECL. The higher stability or the longer lifetime of radicals will give higher ECL because there is a higher probability for the reactants to meet in the diffusion layer.

\section{Reductive Oxidation Co-reactants}

\section{Peroxydisulfate $\left(\mathrm{S}_{2} \mathrm{O}_{8}{ }^{2-}\right)$}

Peroxydisulfate is known as the first reductive oxidation co-reactant. By applying a negative potential to the $\left[\mathrm{Ru}(\mathrm{bpy})_{3}\right]^{2+} /$ peroxydisulfate system, ECL is generated. When a negative potential is applied, peroxydisulfate generates a strongly oxidizing intermediate radical, $\mathrm{SO}_{4}^{-}$, which will then oxidize $\left[\mathrm{Ru}(\mathrm{bpy})_{3}\right]^{2+}$ to become $\left[\mathrm{Ru}(\mathrm{bpy})_{3}\right]^{3+}$. $\left[\mathrm{Ru}(\mathrm{bpy})_{3}\right]^{+}$that is reduced at the electrode reacts with $\left[\mathrm{Ru}(\mathrm{bpy})_{3}\right]^{3+}$ generating an excited state that will emit light when it goes back to the ground state $[2,56]$.

\section{Hydrogen peroxide}

Bard's group studied the ECL of the $\left[\mathrm{Ru}(\mathrm{bpy})_{3}\right]^{2+}$ system with $\mathrm{H}_{2} \mathrm{O}_{2}$ as a co-reactant at $\mathrm{pH} 7.5$ using phosphate buffer solution. Electroreduction of $\mathrm{H}_{2} \mathrm{O}_{2}$ generates hydroxyl radicals to provide electron transfer for the reaction with $\left[\mathrm{Ru}(\mathrm{bpy})_{3}\right]^{2+}$, generating an excited state that can emit light when it goes back to the ground state $[2,56]$. The ECL intensity depends on the concentrations of the luminophore and co-reactant.

\section{Oxygen}

In the annihilation pathway, oxygen is known to have a quenching effect on ECL. Nevertheless, it was reported that oxygen species could trigger the ECL of $\left[\mathrm{Ru}(\mathrm{bpy})_{3}\right]^{2+}$ at a GC electrode at $-0.4 \mathrm{~V}$. The mechanism of this co-reactant is different from the typical reductiveoxidation mechanism. Oxygen is reduced at the electrode and generates a highly oxidizing intermediate; then, this intermediate reacts with $\mathrm{H}_{2} \mathrm{O}$ to form radical hydroxyl. This radical is the one that reacts with a luminophore and promotes the luminophore to its excited state. However, since oxygen is reduced, it is still classified as a reductive oxidation co-reactant $[2,56]$.

\section{In situ Co-Reactants}

In situ generation of co-reactants is studied to produce co-reactants without adding the co-reactant itself, so it will be more environmentally friendly, use less chemicals, and eventually cost less. Hydrogen peroxide is the most studied co-reactant produced via in situ generations. Most of the study uses the help of glucose oxidase (GOx) enzyme because hydrogen peroxide is the side product of the enzymatic reaction. GOx is anchored at the AuNPs-multi carbon walls nanotubes (MCWNTs) and immobilized at the glassy carbon electrode to amplify the ECL signal from the reaction of luminol- $\mathrm{H}_{2} \mathrm{O}_{2}$ as the product reaction of glucose with GOx [58]. To enhance the GOx immobilization on the electrode surface, a hybridization chain reaction (HCR) was reported [59]. Using HCR, a large amount of GOx will be attached to the surface of the electrode. These GOx will catalyze glucose to produce $\mathrm{H}_{2} \mathrm{O}_{2}$ as a side product. This $\mathrm{H}_{2} \mathrm{O}_{2}$ will act as a co-reactant that enhances the ECL signal 
from luminol. Eventually, it will increase the sensitivity of the immunosensor.

In situ generations of hydrogen peroxide are also reported with boron-doped diamond (BDD) electrode, a promising alternative electrode that can maintain the analytical applicability of the system development, such as the sensitivity of the technique. At the same time, it can overcome ECL co-reactant issues such as biomolecules interference and toxicity. Using BDD electrodes for in situ generation has more advantages due to the absence of GOx, an enzyme that requires special treatment and is economically ineffective.

The BDD electrode is known to have a unique ability as it can be operated at an extremely high oxidation potential in water solutions [61-62]. Accordingly, it can efficiently oxidize $\mathrm{SO}_{4}{ }^{2-}$ into a reactive co-reactant, $\mathrm{S}_{2} \mathrm{O}_{8}{ }^{2-}$. Irkham et al. [62] reported the in situ production of $\mathrm{S}_{2} \mathrm{O}_{8}{ }^{2-}$ with a $\left[\mathrm{Ru}(\mathrm{bpy})_{3}\right]^{2+} / \mathrm{S}_{2} \mathrm{O}_{8}{ }^{2-}$ system at a BDD electrode in which the ECL intensity increased proportionally to the concentration of $\mathrm{SO}_{4}{ }^{2-}$, reaching up to $\sim 0.6 \mathrm{M}$, indicating possible implications for analytical uses of the proposed procedure.

In situ production of the hydrogen peroxide coreactant has also been reported in carbonate solution using a BDD electrode with $\left[\mathrm{Ru}(\mathrm{bpy})_{3}\right]^{2+}$ as a luminophore. The system uses the unique characteristics of BDD to promote the oxidation of carbonate $\left(\mathrm{CO}_{3}{ }^{2-}\right)$ into peroxydicarbonate $\left(\mathrm{C}_{2} \mathrm{O}_{6}{ }^{2-}\right) \cdot \mathrm{C}_{2} \mathrm{O}_{6}{ }^{2-}$ further reacts with water to generate reactive hydrogen peroxide as a coreactant. Emission of ECL is triggered by hydroxyl radicals $(\mathrm{OH} \bullet)$, the product of the reduction of hydrogen peroxide. This $\mathrm{OH}$ • will react with the reduced $\left[\mathrm{Ru}(\mathrm{bpy})_{3}\right]^{3+}$ molecules to generate excited states, emitting light when the electron goes back to the ground state [1]. The non-enzymatic in situ co-reactant studies may be a significant step when it combines with ECLIA because it requires less reagent, increasing sensitivity. The behavior of in situ co-reactant for ECLIA applications must be studied since it is interesting enough to fabricate a costeffective but sensitive biosensor.

\section{Criteria of Co-Reactants}

Although there are various types of co-reactants, there are certain criteria that must be fulfilled in order to designate excellent ECL co-reactant systems. The coreactant must have good solubility in the reaction medium as the ECL intensity is proportional to the coreactant concentration. It must also be electroactive, so it can be easily oxidized or reduced on the electrode surface when potential is applied. On the other hand, a co-reactant and its redox must have no quenching effect that can suppress the ECL intensity and have no electrochemical background in the swept potential. In addition, good stability of the intermediate species of the co-reactant is necessary to provide enough time to react with luminophores to form the excited state, while the high rate of reaction between the reduced and oxidized intermediates and luminophores is also needed $[2,24,56]$.

\section{- ELECTRODE IN ECL SYSTEMS}

The ECL phenomenon occurs at electrodes. The electron transfers depend on the electrode. Accordingly, electrodes employed in ECL systems are critical. Many different electrodes have been studied, and it can be classified into a) noble electrodes; b) carbon-based electrodes; c) transparent electrodes; and d) disposable electrodes $[2,63]$. In this section, the reported electrodes will be discussed. An optimal electrode material for the ECL systems, particularly in immunoassay applications, will be suggested.

\section{Noble Electrodes}

Platinum (Pt) and Gold ( $\mathrm{Au})$ are electrode materials used mainly in electrochemistry due to their fast-kinetic electron transfer reactions. These two noble electrodes are also widely used in ECL for the said reason $[2,5]$. For immunoassay applications that have to be in aqueous environments, $\mathrm{Pt}$ has some limitations because $\mathrm{Pt}$ is highly reactive towards water, which causes oxidation to produce platinum oxide and can generate bubbles on the electrode surface [10]. High potential is needed to generate ECL emission, but hydrogen revolution and oxides occur at high potentials [63]. To overcome these limitations, Pt must be modified or coated to decrease oxide formation. So higher amount of TPrA can be oxidized, and eventually, higher ECL intensity is produced. 
Although Au has an identical drawback, namely the formation of an oxide layer, the Au electrode has more electrochemical applications in an aqueous environment. The Au electrode shows higher ECL intensity than using the Pt electrode in the same experimental conditions [6566]. The Au electrode has also excellent biocompatibility and photostability, so it is a suitable electrode for immunoassay applications.

ECL systems with TPrA as a co-reactant, a relatively hydrophobic organic molecule, are well oxidized on hydrophobic electrodes such as carbon materials, but not on metals because they are covered by water and a hydrophilic oxide layer. Hence, both Pt and Au electrodes are better to be modified first.

Besides the hydrophobicity, the number of electrons in the electrode can also affect the ECL intensities. More electrons means higher current and in principle can lead to higher ECL. High current can be obtained by fast electron transfer and fast adsorption of the TPrA on the electrode surface. In an inorganic molecule such as TPrA, electron transfer is related to molecule adsorption on the electrode surface, and it is called inner sphere electron transfer. For inorganic molecules, such as $\left[\mathrm{Ru}(\mathrm{bpy})_{3}\right]^{2+}$, the electron transfer does not involve the adsorption step, and it is called "outer sphere electron transfer". This adsorption process is very important and is affected by the hydrophobicity and hydrophilicity of the electrode surface. Faster adsorption will give faster electron transfer, and eventually give a higher current and ECL intensity.

\section{Carbon-Based Electrodes}

Carbon-based electrodes are widely used in electrochemistry. Due to the co-reactant's fast kinetics heterogeneous electron transfer, carbon is suitable for coreactant-based ECL $[2,63,66]$. Carbon is one of the most popular electrodes for ECLIA application. The glassy carbon electrode (GCE) is the most used electrode to generate emission in the ECL system, but recent studies reported using carbon nanomaterials to give higher ECL intensity and more suitable applications. To increase the surface area, carbon is formed into a nano-sized feature. Eventually, it will enhance electrical conductivity and stability. Carbon nanomaterials also provide biorecognition, and due to their nano sized feature, they have unique properties and versatility. Carbon nanomaterial facilitates various types of analyte detection $[63,67]$.

\section{Transparent Electrodes}

The transparent electrode is also used in ECL application due to the importance of imaging technique, which in ECL is combined with microscopes [63]. Using a transparent electrode for ECL is favorable for the imagery of biological samples. Using autofluorescence may increase noise during analysis, while the signal-tonoise ratio in ECL systems is expected to increase. There are two types of transparent electrodes used in ECL: first, glass/metal oxide, such as Indium Tin Oxide (ITO) and fluorine-doped tin oxide (FTO), and carbon-based electrodes on glass or polymer support [63]. Heterogeneous electron transfer of co-reactants in the transparent electrode is affected by the degrees of transparency, causing typical electrochemical and surface properties [63]. Beads to mimic actual biological samples have been visualized with the ECL technique using ITO electrodes [68] and transparent carbon nanotubes [69].

\section{Paper and Disposable Electrodes}

Point of care testing (PoCT) diagnostics has been widely studied due to their user-friendly and straightforward methods. ECL developed paper and disposable electrodes to adapt to PoCT methods in order to create applicable, simple, user-friendly yet sensitive methods. Paper and disposable electrodes are made by using microfluidic papers fixed onto the surface of screen-printed electrodes (SPE),. The microfluidic paper is filled with luminophores, so when DBAE as a coreactant is injected into the electrode, the ECL signal could be observed [7,63]. Hogan and co-workers [70] developed this type of electrode, where the ECL signal can be detected using both a conventional detector and a camera phone as a photodetector. The digital image from the cell phone camera can be analyzed according to the red pixel intensity. The detection limit of DBAE with the camera reached $250 \mu \mathrm{M}$ while using a conventional 

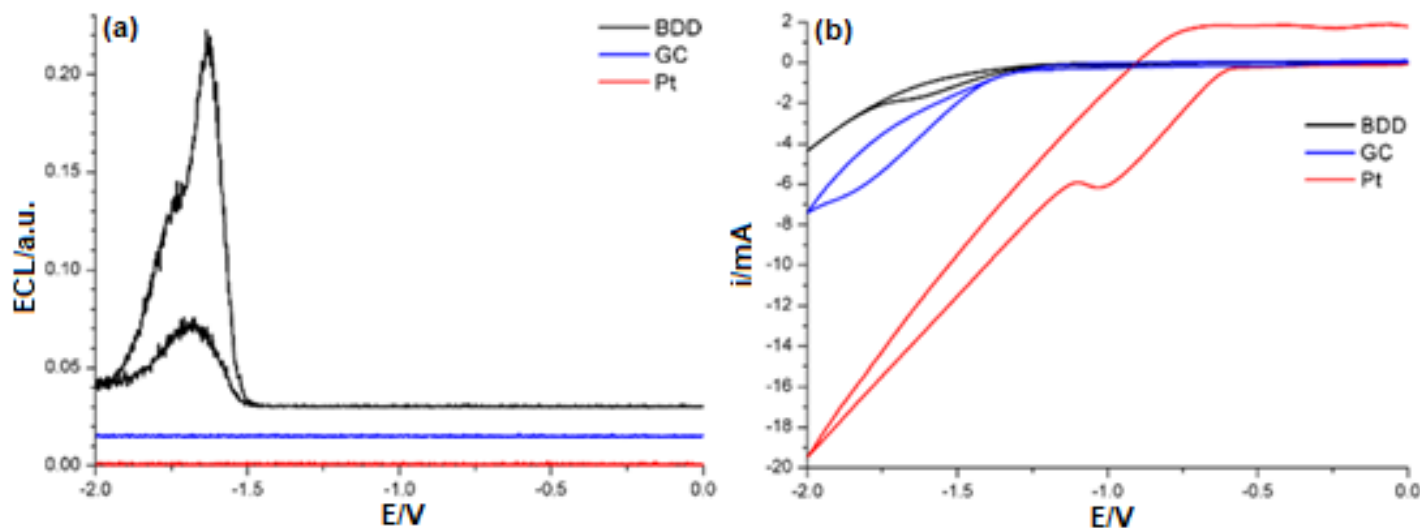

Fig 5. ECL (a) and CV (b) were compared using BDD (black), GC (blue) and Pt (red) electrodes of $10 \mu \mathrm{M}\left[\mathrm{Ru}(\text { bpy) }]_{3}\right]^{2+}$ and $100 \mu \mathrm{M} \mathrm{S}_{2} \mathrm{O}_{8}{ }^{2-}$ in $200 \mathrm{mM} \mathrm{PB}$. The scan rate was $100 \mathrm{mV} / \mathrm{s}$, and the $\mathrm{pH}$ was 6.8. In part a, the curve has been moved for clarity. Reprinted with permission (Anal. Chem., 2018, 90 (21), 12959-12963), Copyright (2018) American Chemical Society [71]

photodetector. A lower detection limit could be obtained. Adapting this principle of study, some biological samples could be detected using PoCT methods.

\section{Boron-Doped Diamond (BDD) Electrode}

In recent years, $\mathrm{BDD}$ has gained attention in the electrochemical field due to its unique properties, including its low background current and wide potential window and also its high physical and chemical stability at high potential applications. It also has better resistance to fouling compared to other conventional electrodes $[50,63]$. In particular, the broad potential window and higher overpotential for hydrogen evolution reaction, compared to common electrodes such as $\mathrm{Pt}, \mathrm{Au}$, and GC, make BDD highly suitable for reductive-oxidation ECL by avoiding interferences from hydrogen evolution $[1,62]$.

ECL emission was confirmed on the BDD film. Compared to GCE and polycrystalline $\mathrm{Pt}, \mathrm{BDD}$ has outstanding performance, including fast charge transfer reaction rates, wide potential window, low background current, high sensitivity, and high chemical stability [63]. Fig. 5 shows a comparison of the ECL co-reactant system using $\left[\mathrm{Ru}(\mathrm{bpy})_{3}\right]^{2+} /$ peroxydisulfate using $\mathrm{BDD}, \mathrm{Pt}$, and GCE [71]. BDD shows a significant ECL intensity reduction and oxidation potential, while Pt and GCE show no signal. BDD has expansive potential windows and high overpotential. The hydrogen evolution reaction on Pt and GCE affects the ECL emission. Compared to
$\mathrm{GC}$ and $\mathrm{Pt}$, the potential of proton reduction on BDD is higher, which makes BDD perform well in reducing and oxidizing ECL in an aqueous solution. Having these excellent properties and the ability to generate in situ coreactants, studies of ECLIA using BDD electrodes must be considered.

\section{- ECL INSTRUMENTATION}

Despite the availability of commercial ECL instrumentation, most of the reported ECL studies were performed with self-built ECL instruments [2]. The selfbuilt instruments generally consist of two parts: the electrochemical and optical devices [72]. The electrochemical device acts as the general electrochemical cell in which the design of the cell depends on the purpose of the research. The optical device is the photodetector used to capture the ECL signal of the product of the reaction. The most commonly used photodetectors include the Avalanche Photodiodes (APD), the Photomultiplier tubes (PMTs), and the Charged coupled device (CCD) cameras in which two devices are used together, therefore when the measurement is performed, both the electrochemical signal and the ECL intensity will be simultaneously generated.

An example of a commercial ECL instrument is the ORIGEN analyzer (formerly IGEN Gaitersburg MD), but this instrument is no longer available due to some 
business affairs. Nevertheless, the principle of this instrument was adapted to ECLIA applications as shown in Fig. 6 [7]. Based on this principle, immunoassay was conducted using magnetic beads for easy immobilization and separation. The use of magnetic beads can facilitate the bioconjugation of the immunocomplex, which eventually increases the sensitivity and selectivity of ECLIA.

Fig. 7 is an example of commercial instrumentation of ECL called the M-SERIES ${ }^{\star} 384$ Analyzer. It is a highthroughput system for detecting and measuring biomolecular interactions. The system of this ECL instrument employs how to handle the reagent, the detection system, and the analysis process which had been patented by the BioVeris corporation in the USA [74]. Another patent about ECL is explained by the principle of instrumentation with sandwich immunoassay using magnetic particles [75]. ECLIA is usually measured in a flow system. An ECL cell for flow systems has been patented by Kumar, et al. explaining the components and assay methods that use this system [76].

\section{- ECLIA APPLICATION}

ECL has many analytical applications; one of the most powerful applications is in the biosensor area. In immunoassay application, ECL has become the method to detect many biological matrices, especially cancer biomarkers. In this section, the applications of ECLIA will be divided based on the analyte detection, which includes bacteria, cancer and tumor biomarkers, other diseases, protein, agriculture pollutant, dye, etc. The following list shows some analytes that can be detected using ECLIA and other parameters.

\section{Bacteria}

Bacteria detection using ECL biosensors was first reported 20 years ago, and the methods have continually improved [6]. In ECLIA, E. Coli was detected using both direct and sandwich format with Ru1-labeled AMP on the $\mathrm{Au}$ electrode system. Both formats can detect $E$. coli with a detection limit of $2.3 \times 10^{2} \mathrm{CFU} / \mathrm{mL}$ and $1.2 \times 102$ $\mathrm{CFU} / \mathrm{mL}$ for direct and sandwich format, respectively [77]. Label-free ECLIA with luminol as the luminophore

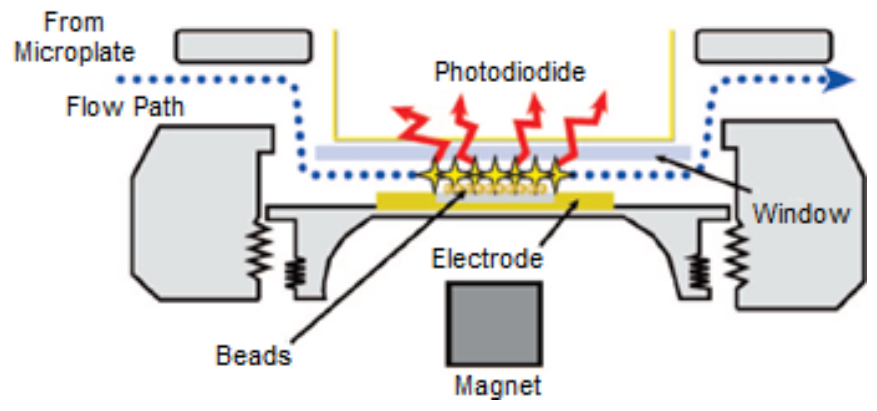

Fig 6. Schematic diagram of a flow system based on BioVeris technology. The magnetic beads were used as solid support for the binding reaction and ECL measurement. Reprinted with permission from (Chem. Rev., 2008, 108 (7), 2506-2553), Copyright (2008) American Chemical Society

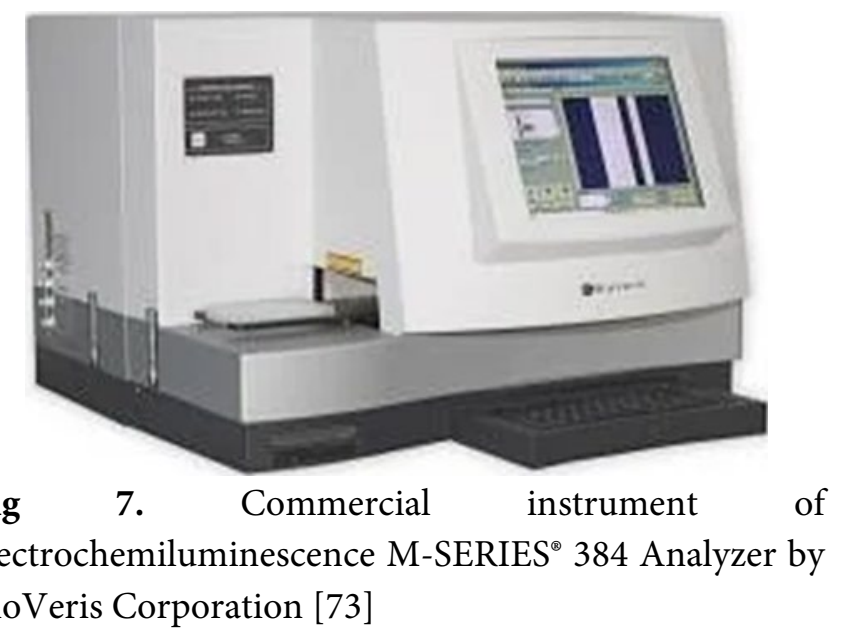

can also detect $S$. aureus with a detection limit of $3.1 \times$ $10^{2} \mathrm{CFU} / \mathrm{mL}$. The detection chemistry of this immunosensor is based on the specific binding of $S$. aureus protein $\mathrm{A}$ in the cell wall with immunoglobulin G (IgG). The IgG was immobilized on the carboxyl graphene as a carrier, playing a role as an ECL immunosensor [17].

\section{Cancer, Tumor Detection Diagnosis}

Many studies have reported ECLIA for its application in cancer and tumor detection diagnosis [6]. ECLIA detects cancer biomarkers so it can diagnose cancer [7]. Studies show that ECLIA can detect various biomarkers, such as $\alpha$-fetoprotein as a hepatocellular cancer marker, prostate-specific antigen as a prostate 
Table 1. Some examples of analytes that ECLIA could detect

\begin{tabular}{|c|c|c|c|c|c|c|}
\hline Analyte & $\begin{array}{l}\text { Type of } \\
\text { ECLIA }\end{array}$ & Label & Co-reactant & Working Electrode & LOD & ref \\
\hline E. coli & Label free & $\begin{array}{l}\text { Ruthenium } \\
\text { complex- } \\
\text { labelled } \\
\text { concanavalin A } \\
\text { as biological } \\
\text { recognition }\end{array}$ & TPrA & $\begin{array}{l}\text { graphite electrode modified } \\
\text { with SWNTs }\end{array}$ & 127 cells $/ \mathrm{mL}$ & {$[84]$} \\
\hline P. aeruginosa & Label free & Luminol & Oxygen & $\begin{array}{l}\text { Glassy carbon electrode } \\
\text { modified carboxyl graphene }\end{array}$ & $56 \mathrm{CFU} / \mathrm{mL}$ & {$[13]$} \\
\hline Ochratoxin A & Label free & $\mathrm{CdS}-\mathrm{Fe}_{3} \mathrm{O}_{4}$ & $\mathrm{H}_{2} \mathrm{O}_{2}$ & GCE & $2 \mathrm{pg} / \mathrm{mL}$ & {$[85]$} \\
\hline Diclofenac & Label free & $\begin{array}{l}\text { polymer } \\
\text { functionalized } \\
\text { graphene oxide }\end{array}$ & $\mathrm{SO}_{4}{ }^{2-}$ & $\begin{array}{l}\text { GCE modified with } \mathrm{Au} \\
\text { nanorods }\end{array}$ & $0.33 \mathrm{pg} / \mathrm{mL}$ & {$[86]$} \\
\hline $\begin{array}{l}\text { neuron-specific enolase } \\
\text { (NSE) }\end{array}$ & Label free & CdTe-QDs & $\mathrm{SO}_{4}^{2-}$ & $\begin{array}{l}\text { single-walled carbon } \\
\text { nanohorns (SWCNHs) }\end{array}$ & $4.4 \times 10^{-10} \mathrm{~g} / \mathrm{L}$ & {$[87]$} \\
\hline Brombuterol & Direct IA & CdSe-QDs & $\mathrm{S}_{2} \mathrm{O}_{8}{ }^{2-}$ & GCE modified with AuNPs & $1.5 \mathrm{pg} / \mathrm{mL}$ & {$[88]$} \\
\hline$\alpha$-fetoprotein & Sandwich IA & CdTe-QDs & $\mathrm{S}_{2} \mathrm{O}_{8}{ }^{2-}$ & GCE & $0.32 \mathrm{ng} / \mathrm{mL}$ & {$[78]$} \\
\hline Sudan I & $\begin{array}{l}\text { Competitive } \\
\text { IA }\end{array}$ & $\begin{array}{l}\text { CdSe@CdS QDs } \\
\text { with e Pd/Au } \\
\text { CSNs as carrier }\end{array}$ & $\mathrm{S}_{2} \mathrm{O}_{8}{ }^{2-}$ & $\begin{array}{l}\text { GCE coated with Au } \\
\text { nanorods functionalized } \\
\text { graphene oxide }\end{array}$ & $0.3 \mathrm{pg} / \mathrm{mL}$ & [89] \\
\hline C-peptide & Label free & Luminol & - & ITO modified with AuNPs & $0.0142 \mathrm{ng} / \mathrm{mL}$ & {$[90]$} \\
\hline Ractopamine & $\begin{array}{l}\text { Competitive } \\
\text { IA }\end{array}$ & $\begin{array}{l}\text { CdSe } \\
\text { QDs/PDDA- } \\
\text { GN/AuNPs }\end{array}$ & $\mathrm{S}_{2} \mathrm{O}_{8}{ }^{2-}$ & GCE & $2.6 \mathrm{pg} / \mathrm{mL}$ & {$[91]$} \\
\hline Aflatoxin B1 & Label free & Luminol & - & $\begin{array}{l}\text { Magnetic GCE modified } \\
\text { with } \mathrm{Fe}_{3} \mathrm{O}_{4} \text {-NFs }\end{array}$ & $0.02 \mathrm{ng} / \mathrm{mL}$ & {$[92]$} \\
\hline $\begin{array}{l}\text { NT-proBNP (biomarker } \\
\text { heart failure) }\end{array}$ & Label-free & Ti doped $\mathrm{BiOBr}$ & $\mathrm{S}_{2} \mathrm{O}_{8}{ }^{2-}$ & GCE & $0.33 \mathrm{pg} / \mathrm{mL}$ & {$[93]$} \\
\hline Cardiac troponin I & Sandwich IA & Luminol & $\mathrm{H}_{2} \mathrm{O}_{2}$ & PEI-RGO modified GCE & $3.3 \mathrm{pg} / \mathrm{mL}$ & {$[94]$} \\
\hline Prostate-specific antigen & Direct IA & Luminol & $\mathrm{H}_{2} \mathrm{O}_{2}$ & GCE & $0.927 \mathrm{pg} / \mathrm{mL}$ & [19] \\
\hline $\begin{array}{l}\text { microcystin-leucine- } \\
\text { arginine (MCLR) }\end{array}$ & Sandwich IA & CdS-QDs & $\mathrm{S}_{2} \mathrm{O}_{8}{ }^{2-}$ & GCE modified AuNPs & $0.0028 \mu \mathrm{g} / \mathrm{L}$ & {$[95]$} \\
\hline S. aureus & Label free & Luminol & Oxygen & $\begin{array}{l}\text { GCE modified carboxyl } \\
\text { graphene }\end{array}$ & $\begin{array}{l}3.1 \times 10^{2} \\
\mathrm{CFU} / \mathrm{mL}\end{array}$ & {$[17]$} \\
\hline $\begin{array}{l}\text { Carcinoembryonic } \\
\text { antigen (CEA) }\end{array}$ & Sandwich & CdSe NCs & $\mathrm{S}_{2} \mathrm{O}_{8}{ }^{2-}$ & GCE & $0.10 \mathrm{fg} / \mathrm{mL}$ & {$[96]$} \\
\hline $\begin{array}{l}\text { Genetically modified } \\
\text { organisms (GMOs) }\end{array}$ & Label free & Luminol & - & $\begin{array}{l}\text { CNPs-conjugated antibody } \\
\text { for PAT/bar protein } \\
\text { modified GCE }\end{array}$ & $0.050 \mathrm{ng} / \mathrm{mL}$ & [97] \\
\hline Cancer antigen 125 & Sandwich & $\begin{array}{l}\text { CdTe-QDs } \\
\text { coated carbon } \\
\text { microspheres }\end{array}$ & $\mathrm{S}_{2} \mathrm{O}_{8}{ }^{2-}$ & SPCPE & $2.5 \mathrm{mU} / \mathrm{mL}$ & {$[98]$} \\
\hline $\begin{array}{l}\text { Human chorionic } \\
\text { gonado-trophin (HCG) }\end{array}$ & Sandwich & $\mathrm{Ru}(\mathrm{bpy})_{3}{ }^{2+}$ & $\begin{array}{l}\text { polyethylenimine } \\
(\mathrm{PEI})\end{array}$ & R-CNTs-Nf & $0.171 \mathrm{IU} / \mathrm{mL}$ & [99] \\
\hline Protein cancer biomarker & Sandwich & $\mathrm{Ru}(\mathrm{bpy})$-silica & TPrA & $\begin{array}{l}\text { Pyrolytic graphite modified } \\
\text { SWCNTs }\end{array}$ & $40 \mathrm{pg} / \mathrm{mL}$ & [100] \\
\hline
\end{tabular}


cancer marker, pancreatic cancer marker, gastric carcinoma, lung carcinoma, and breast carcinoma [79-83].

\section{Other Diseases}

Other than cancer, ECLIA has also been used to diagnose other diseases such as heart disorders and rabies by detecting the antibody $[7,83]$. Human cardiac troponin I as a heart disease biomarker was successfully detected via sandwich immunoassay with a detection limit of 2 $\mathrm{pg} / \mathrm{mL}$ [7]. Based on the specific antigen-antibody interaction and the bovine serum albumin (BSA), the "Au-GN/PrV (Ag)/PrV antibody (Ab1)/biotinylated IgG $\left(\mathrm{B}-\mathrm{Ab}_{2}\right) / \mathrm{SA} /$ biotinylated $\left[\mathrm{Ru}(\mathrm{bpy})_{3}\right]^{2+}$-encapsulated SNPs (B-Ru@SNPs)" triply amplified immunosensor could be fabricated and can detect monoclonal pseudorabies virus $(\mathrm{PrV})$ antibody with a detection limit of $0.4 \mathrm{pg} / \mathrm{mL}$ [83].

Many analytes can be detected using the ECLIA method. It depends on the antibody or antigen that is used in the fabrication of the biosensor. Table 1 shows some analytes that can be detected using ECLIA and the previously explained parameters used to fabricate the ECLIA.

\section{- CONCLUSIONS AND FUTURE PERSPECTIVE}

As described in this review, ECLIA has been one of the most promising assays with superior properties and contributed to clinical diagnostics and environmental analysis. ECLIA has also been explored as imaging biosensors for the mapping of cell surface proteins. Furthermore, the development of ECLIA is moving towards PoCT, using a camera phone as the photodetector for the ECL emission, even though it is currently still in the early stages of study.

Despite the apparent advances in ECLIA development, several important issues should be addressed, in order for ECLIA to be able to be developed as an excellent assay and move forward into practical applications. In the fundamental research of ECLIA, ECL labels or luminophores, co-reactants, electrodes or/and immobilization support, also strategies of bioconjugation are some features that affect the ECL signal. Therefore, developing the above factors is essential to create an accurate, sensitive, and selective analytical method. Synthesis of new ECL labels that can emit higher ECL intensity and suit the system is also crucial. Modification of electrodes or/and immobilization support can easily cause the conjugation of biological recognition elements with ECL labels or luminophores, hence the most commonly reported ECL labels are the conjugation between the biological sensing agent and the ECL reagent. ECLIA requires electrodes with good conductivity, low background signal, large potential window, and high overpotential since it can indirectly affect the ECL signal. For example, the boron-doped diamond (BDD) electrode or modified BDD electrodes need to be considered due to the many advantages regarding ECL.

In applied research, ECLIA should move towards practical applications. ECLIA is required to have superb sensitivity and selectivity yet can easily be manufactured. Low-cost ECLIA must be considered as an essential issue for practical applications, but it must compete with other IAs. To improve the ECLIA performance, better immobilization methods, exploring new environmentally friendly materials, and developing highly efficient ECL systems must be considered. This can be done if we can comprehend the critical test parameters of ECLIA, such as the limit of detection, range of detection, detection format, stability, short analytical time, specificity, and selectivity. Moreover, a comprehensive understanding of the manufacturing process, such as housing design, packaging, and target cost, is essential if ECLIA is to be proposed for practical applications.

\section{- ACKNOWLEDGMENTS}

The authors would like to acknowledge the financial support provided by Directorate General of Higher Education, Ministry of Education and Culture, Republic of Indonesia via PMDSU scholarship, Grant No. NKB-432/UN2.RST/HKP.05.00/2020.

\section{- REFERENCES}

[1] Irkham, Fiorani, A., Valenti, G., Kamoshida, N., Paolucci, F., and Einaga, Y., 2020, Electrogenerated chemiluminescence by in situ production of coreactant hydrogen peroxide in carbonate aqueous 
solution at a boron-doped diamond electrode, J. Am. Chem. Soc., 142 (3), 1518-1525.

[2] Miao, W., 2008, Electrogenerated chemiluminescence and its biorelated applications, Chem. Rev., 108 (7), 2506-2553.

[3] Dennany, L., 2019, "Electrochemiluminescence Fundamentals and Analytical Applications" in Electrochemistry: Volume 15, Eds. Banks, C., and McIntosh, S., The Royal Society of Chemistry, 96146.

[4] Fiorani, A., Valenti, G., Iurlo, M., Marcaccio, M., and Paolucci, F., 2018, Electrogenerated chemiluminescence: A molecular electrochemistry point of view, Curr. Opin. Electrochem., 8, 31-38.

[5] Richter, M.M., 2004, Electrochemiluminescence (ECL), Chem. Rev., 104 (6), 3003-3036.

[6] Gross, E.M., Maddipati, S.S., and Snyder, S.M., 2016, A review of electrogenerated chemiluminescent biosensors for assays in biological matrices, Bioanalysis, 8 (19), 2071-2089.

[7] Muzyka, K., 2014, Current trends in the development of the electrochemiluminescent immunosensors, Biosens. Bioelectron., 54, 393-407.

[8] Vashist, S.K., and Luong, J.H.T., 2018, "Chapter 1 Immunoassays: An Overview" in Handbook of Immunoassay Technologies, Academic Press, 1-18.

[9] Bouffier, L., and Sojic, N., 2019, "Chapter 1. Introduction and Overview of Electrogenerated Chemiluminescence" in Analytical Electrogenerated Chemiluminescence: From Fundamentals to Bioassays, Eds. Sojic, N., The Royal Society of Chemistry, 1-28.

[10] Valenti, G., Fiorani, A., Li, H., Sojic, N., and Paolucci, F., 2016, Essential role of electrode materials in electrochemiluminescence applications, ChemElectroChem, 3 (12), 1990-1997.

[11] Peng, S., and Zhang, X., 2012, Electrodeposition of CdSe quantum dots and its application to an electrochemiluminescence immunoassay for $\alpha$ fetoprotein, Microchim. Acta, 178 (3), 323-330.

[12] Li, F., Yu, Y., Cui, H., Yang, D., and Bian, Z., 2013, Label-free electrochemiluminescence immunosensor for cardiac troponin I using luminol functionalized gold nanoparticles as a sensing platform, Analyst, 138 (6), 1844-1850.

[13] Yue, H., He, Y., Fan, E., Wang, L., Lu, S., and Fu, Z., 2017, Label-free electrochemiluminescent biosensor for rapid and sensitive detection of Pseudomonas aeruginosa using phage as highly specific recognition agent, Biosens. Bioelectron., 94, 429-432.

[14] Sun, C., Liao, X., Jia, B., Shi, L., Zhang, D., Wang, R., Zhou, L., and Kong, W., 2020, Development of a ZnCdS@ZnS quantum dots-based label-free electrochemiluminescence immunosensor for sensitive determination of aflatoxin B1 in lotus seed, Microchim. Acta, 187 (4), 236.

[15] Shu, J., Shen, W., and Cui, H., 2015, Ultrasensitive label-free electrochemiluminescence immunosensor based on $\mathrm{N}$-(4-aminobutyl)- $\mathrm{N}$-ethylisoluminolfunctionalized graphene composite, Sci. China Chem., 58 (3), 425-432.

[16] Rizwan, M., Mohd-Naim, N.F., Keasberry, N.A., and Ahmed, M.U., 2017, A highly sensitive and label-free electrochemiluminescence immunosensor for beta 2-microglobulin, Anal. Methods, 9 (17), 2570-2577.

[17] Yue, H., Zhou, Y., Wang, P., Wang, X., Wang, Z., Wang, L., and $\mathrm{Fu}, \mathrm{Z}$., 2016, A facile label-free electrochemiluminescent biosensor for specific detection of Staphylococcus aureus utilizing the binding between immunoglobulin $\mathrm{G}$ and protein $\mathrm{A}$, Talanta, 153, 401-406.

[18] Hou, F., Fu, X.L., Hu, X.B., Cao, J.T., Ma, S.H., and Liu, Y.M., 2020, Label-free electrochemiluminescence immunosensor for the determination of cardiac troponin I using a cadmium sulfide-molybdenum (IV) sulfide nanocomposite modified glassy carbon electrode, Anal. Lett., 53 (9), 1416-1427.

[19] Ma, H., Zhao, Y., Li, L., Wang, H., and Wei, Q., 2018, Label-free electrochemiluminescent immunosensor for detection of prostate specific antigen based on mesoporous graphite-like carbon nitride, Talanta, 188, 729-735.

[20] Wu, D., Liu, Y., Wang, Y., Hu, L., Ma, H., Wang, G., and Wei, Q., 2016, Label-free 
electrochemiluminescent immunosensor for detection of prostate specific antigen based on aminated graphene quantum dots and carboxyl graphene quantum dots, Sci. Rep., 6, 20511.

[21] Miao, W., and Lu, L., 2019, "Chapter 3. Efficient ECL Luminophores" in Analytical Electrogenerated Chemiluminescence: From Fundamentals to Bioassays, Eds. Sojic, N., The Royal Society of Chemistry, 59-91.

[22] Liu, Z., Qi, W., and Xu, G., 2015, Recent advances in electrochemiluminescence, Chem. Soc. Rev., 44 (10), 3117-3142.

[23] Tokel, N.E., and Bard, A.J., 1972, Electrogenerated chemiluminescence. IX. Electrochemistry and emission from systems containing tris(2,2'-bipyridine) ruthenium(II) dichloride, J. Am. Chem. Soc., 94 (8), 2862-2863.

[24] Miao, W., Choi, J., and Bard, A.J., 2002, Electrogenerated chemiluminescence 69: The tris(2,2'-bipyridine)ruthenium(II), $\left(\mathrm{Ru}(\mathrm{bpy})_{3}{ }^{2+}\right) /$ trin-propylamine (TPrA) system revisited - A new route involving $\operatorname{TPrA}^{\circ+}$ cation radicals, J. Am. Chem. Soc., 124 (48), 14478-14485.

[25] Liu, X., Shi, L., Niu, W., Li, H., and Xu, G., 2007, Environmentally friendly and highly sensitive ruthenium(II) tris(2,2'-bipyridyl) electrochemiluminescent system using 2(dibutylamino)ethanol as co-reactant, Angew. Chem. Int. Ed., 46 (3), 421-424.

[26] White, H.S., and Bard, A.J., 1982, Electrogenerated chemiluminescence. 41. Electrogenerated chemiluminescence and chemiluminescence of the $\mathrm{Ru}\left(2,2^{1} \text {-bpy }\right)_{3}{ }^{2+}-\mathrm{S}_{2} \mathrm{O}_{8}{ }^{2-}$ system in acetonitrile-water solutions, J. Am. Chem. Soc., 104 (25), 6891-6895.

[27] Choi, J., and Bard, A.J., 2005, Electrogenerated chemiluminescence (ECL) 79.: Reductive-oxidation ECL of tris(2,2'-bipyridine)ruthenium(II) using hydrogen peroxide as a coreactant in $\mathrm{pH} 7.5$ phosphate buffer solution, Anal. Chim. Acta, 541 (12), 141-148.

[28] Acharya, D., Bastola, P., Le, L., Paul, A.M., Fernandez, E., Diamond, M.S., Miao, W., and Bai, F., 2016, An ultrasensitive electrogenerated immunoassay for specific detection of Zika virus, Sci. Rep., 6 (1), 32227.

[29] Chen, L., Hayne, D.J., Doeven, E.H., Agugiaro, J., Wilson, D.J.D., Henderson, L.C., Connell, T.U., Nai, Y.H., Alexander, R., Carrara, S., Hogan, C.F., Donnelly, P.S., and Francis, P.S., 2019, A conceptual framework for the development of iridium(III) complex-based electrogenerated chemiluminescence labels, Chem. Sci., 10 (37), 8654-8667.

[30] Staffilani, M., Höss, E., Giesen, U., Schneider, E., Hartl, F., Josel, H.P., and De Cola, L., 2003, Multimetallic ruthenium(II) complexes as electrochemiluminescent labels, Inorg. Chem., 42 (24), 7789-7798.

[31] Yu, L., Liu, Y., and Zhou, M., 2016, Improved electrochemiluminescence labels for heterogeneous microbead immunoassay, Anal. Bioanal. Chem., 408 (25), 7095-7103.

[32] Kim, J.I., Shin, I.S., Kim, H., and Lee, J.K., 2005, Efficient electrogenerated chemiluminescence from cyclometalated iridium(III) complexes, J. Am. Chem. Soc., 127 (6), 1614-1615.

[33] Kapturkiewicz, A., Nowacki, J., and Borowicz, P., 2005, Electrochemiluminescence studies of the cyclometalated iridium(III) $\mathrm{L}_{2} \mathrm{Ir}$ (acetyl acetonate) complexes, Electrochim. Acta, 50 (16-17), 33953400 .

[34] Muegge, B.D., and Richter, M.M., 2004, Multicolored electrogenerated chemiluminescence from ortho-metalated iridium(III) systems, Anal. Chem., 76 (1), 73-77.

[35] Kapturkiewicz, A., and Angulo, G., 2003, Extremely efficient electrochemiluminescence systems based on tris(2-phenylpyridine)iridium(III), Dalton Trans., 20, 3907-3913.

[36] Zhou, Y., Li, W., Yu, L., Liu, Y., Wang, X., and Zhou, M., 2015, Highly efficient electrochemiluminescence from iridium(III)) complexes with 2-phenylquinoline ligand, Dalton Trans., 44 (4), 1858-1865.

[37] Shin, I.S., Yoon, S., Kim, J.I., Lee, J.K., Kim, T.H., and Kim, H., 2011, Efficient green-colored electrochemiluminescence from cyclometalated 
iridium(III) complex, Electrochim. Acta, 56 (17), 6219-6223.

[38] Kapturkiewicz, A., 2016, Cyclometalated iridium(III) chelates-A new exceptional class of the electrochemiluminescent luminophores, Anal. Bioanal. Chem., 408 (25), 7013-7033.

[39] Dennany, L., Forster, R.J., White, B., Smyth, M., and Rusling, J.F., 2004, Direct electrochemiluminescence detection of oxidized DNA in ultrathin films containing $\left[\mathrm{Os}(\mathrm{bpy})_{2}(\mathrm{PVP})_{10}\right]^{2+}, J$. Am. Chem. Soc., 2 (20), 8835-8841.

[40] Staninski, K., Lis, S., and Komar, D., 2006, Electrochemiluminescence on $\mathrm{Dy}(\mathrm{III})$ and $\mathrm{Tb}(\mathrm{III})$ doped $\mathrm{Al} / \mathrm{Al}_{2} \mathrm{O}_{3}$ surface electrode, Electrochem. Commun., 8 (7), 1071-1074.

[41] Yang, Y., Zhang, Y., Shu, G., Dong, Q., Zou, L., and Zhu, Y., 2015, Electrochemiluminescence properties of $\mathrm{Tb}(\mathrm{III})$ nicotinic acid complex and its analytical application, J. Lumin., 159, 73-78.

[42] Staninski, K., and Lis, S., 2011, Ultraweak emission of the $\mathrm{Eu}(\mathrm{III})$ ions in cathodic generated electrochemiluminescence, Opt. Mater., 33 (10), 1540-1543.

[43] Lis, S., Staninski, K., and Grzyb, T., 2008, Electrochemiluminescence study of europium(III) complex with coumarin3-carboxylic acid, Int. J. Photoenergy, 2008, 131702.

[44] Xiang, G., Wang, X., Li, M.S.M., Lac, K., Wang, S., and Ding, Z., 2017, Probing excimers of Pt(II) compounds with phenyl-1,2,3-triazolyl and pyridyl1,2,4-triazolyl chelate ligands by means of electrochemiluminescence, ChemElectroChem, 4 (7), 1757-1762.

[45] Dick, J.E., Renault, C., Kim, B.K., and Bard, A.J., 2014, Electrogenerated chemiluminescence of common organic luminophores in water using an emulsion system, J. Am. Chem. Soc., 136 (39), 1354613549.

[46] Liu, J.L., Tang, Z.L., Zhang, J.Q., Chai, Y.Q., Zhuo, Y., and Yuan, R., 2018, Morphology-controlled 9,10diphenylanthracene nanoblocks as electrochemiluminescence emitters for microRNA detection with one-step DNA walker amplification, Anal. Chem., 90 (8), 5298-5305.

[47] Zholudov, Y.T., and Xu, G., 2018, Electrogenerated chemiluminescence at a 9,10diphenylanthracene/polyvinyl butyral film modified electrode with a tetraphenylborate coreactant, Analyst, 143 (14), 3425-3432.

[48] Zhang, Y., Zhang, R., Yang, X., Qi, H., and Zhang, C., 2019, Recent advances in electrogenerated chemiluminescence biosensing methods for pharmaceuticals, J. Pharm. Anal., 9 (1), 9-19.

[49] Fang, C., Li, H., Yan, J., Guo, H., and Yifeng, T., 2017, Progress of the electrochemiluminescence biosensing strategy for clinical diagnosis with luminol as the sensing probe, ChemElectroChem, 4 (7), 1587-1593.

[50] Garcia-Segura, S., Centellas, F., and Brillas, E., 2012, Unprecedented electrochemiluminescence of luminol on a boron-doped diamond thin-film anode. Enhancement by electrogenerated superoxide radical anion, J. Phys. Chem. C, 116 (29), 15500-15504.

[51] Xiuhua, W., Chao, L., and Yifeng, T., 2012, Microemulsion-enhanced electrochemiluminescence of luminol- $\mathrm{H}_{2} \mathrm{O}_{2}$ for sensitive flow injection analysis of antioxidant compounds, Talanta, 94, 289-294.

[52] Huang, Y., Lei, J., Cheng, Y., and Ju, H., 2016, Ratiometric electrochemiluminescent strategy regulated by electrocatalysis of palladium nanocluster for immunosensing, Biosens. Bioelectron., 77, 733-739.

[53] Forster, R.J., 2019, “Chapter 9. ECL of Nanomaterials: Novel Materials, Detection Strategies and Applications" in Analytical Electrogenerated Chemiluminescence: From Fundamentals to Bioassays, Eds. Sojic, N., The Royal Society of Chemistry, 247-273.

[54] Ding, Z., Quinn, B.M., Haram, S.K., Pell, L.E., Korgel, B.A., and Bard, A.J., 2002, Electrochemistry and electrogenerated chemiluminescence from silicon nanocrystal quantum dots, Science, 296 (5571), 1293-1297. 
[55] Algar, W.R., Tavares, A.J., and Krull, U.J., 2010, Beyond labels: A review of the application of quantum dots as integrated components of assays, bioprobes, and biosensors utilizing optical transduction, Anal. Chim. Acta, 673 (1), 1-25.

[56] Yuan, Y., Li, J., and Xu, G., 2019, "Chapter 4. Electrochemiluminescence Coreactants" in Analytical Electrogenerated Chemiluminescence: From Fundamentals to Bioassays, Eds. Sojic, N., The Royal Society of Chemistry, 92-133.

[57] Chang, M.M., Saji, T., and Bard, A.J., 1977, Electrogenerated chemiluminescence. 30. Electrochemical oxidation of oxalate ion in the presence of luminescers in acetonitrile solutions, $J$. Am. Chem. Soc., 99 (16), 5399-5403.

[58] Cao, Y., Yuan, R., Chai, Y., Mao, L., Niu, H., Liu, H., and Zhuo, Y., 2012, Ultrasensitive luminol electrochemiluminescence for protein detection based on in situ generated hydrogen peroxide as coreactant with glucose oxidase anchored AuNPs@MWCNTs labeling, Biosens. Bioelectron., 31 (1), 305-309.

[59] Xiao, L., Chai, Y., Yuan, R., Cao, Y., Wang, H., and Bai, L., 2013, Amplified electrochemiluminescence of luminol based on hybridization chain reaction and in situ generate co-reactant for highly sensitive immunoassay, Talanta, 115, 577-582.

[60] Asai, K., Ivandini, T.A., Falah, M.M., and Einaga, Y., 2016, Surface termination effect of boron-doped diamond on the electrochemical oxidation of adenosine phosphate, Electroanalysis, 28 (1), 177-182.

[61] Ivandini, T.A., Watanabe, T., Matsui, T., Ootani, Y., Iizuka, S., Toyoshima, R., Kodama, H., Kondoh, H., Tateyama, Y., and Einaga, Y., 2019, Influence of surface orientation on electrochemical properties of boron-doped diamond, J. Phys. Chem. C, 123 (9), 5336-5344.

[62] Irkham, Watanabe, T., Fiorani, A., Valenti, G., Paolucci, F., and Einaga, Y., 2016, Co-reactant-ondemand ECL: Electrogenerated chemiluminescence by the in situ production of $\mathrm{S}_{2} \mathrm{O}_{8}{ }^{2-}$ at boron-doped diamond electrodes, J. Am. Chem. Soc., 138 (48), 15636-15641.
[63] Valenti, G., Fiorani, A., Villani, E., Zanut, A., and Paolucci, F., 2019, "Chapter 6. The Essential Role of Electrode Materials in ECL Applications" in Analytical Electrogenerated Chemiluminescence: From Fundamentals to Bioassays, Eds. Sojic, N., The Royal Society of Chemistry, 159-175.

[64] Zu, Y., and Bard, A.J., 2000, Electrogenerated chemiluminescence. 66. The role of direct coreactant oxidation in the ruthenium tris $\left(2,2^{\prime}\right)$ bipyridyl/ tripropylamine system and the effect of halide ions on the emission intensity, Anal. Chem., 72 (14), 3223-3232.

[65] Kitte, S.A., Wang, C., Li, S., Zholudov, Y., Qi, L., Li, J., and $\mathrm{Xu}, \quad \mathrm{G} ., \quad 2016$, Electrogenerated chemiluminescence of tris $\left(2,2^{2}\right.$ bipyridine)ruthenium(II) using N-(3aminopropyl)diethanolamine as coreactant, Anal. Bioanal. Chem., 408 (25), 7059-7065.

[66] Zanut, A., Fiorani, A., Canola, S., Saito, T., Ziebart, N., Rapino, S., Rebeccani, S., Barbon, A., Irie, T., Josel, H.P., Negri, F., Marcaccio, M., Windfuhr, M., Imai, K., Valenti, G., and Paolucci, F., 2020, Insights into the mechanism of coreactant electrochemiluminescence facilitating enhanced bioanalytical performance, Nat. Commun., 11 (1), $1-9$.

[67] Fiorani, A., Merino, J.P., Zanut, A., Criado, A., Valenti, G., Prato, M., and Paolucci, F., 2019, Advanced carbon nanomaterials for electrochemiluminescent biosensor applications, Curr. Opin. Electrochem., 16, 66-74.

[68] Mortet, V., Vlčková Živcová, Z., Taylor, A., Frank, O., Hubík, P., Trémouilles, D., Jomard, F., Barjon, J., and Kavan, L., 2017, Insight into boron-doped diamond Raman spectra characteristic features, Carbon, 115, 279-284.

[69] Valenti, G., Zangheri, M., Sansaloni, S.E., Mirasoli, M., Penicaud, A., Roda, A., and Paolucci, F., 2015, Transparent carbon nanotube network for efficient electrochemiluminescence devices, Chem. Eur. J., 21 (36), 12640-12645.

[70] Hogan, C.F., Francis, P.S., and Doeven, E.H., 2019, "Chapter 8. Multicolour Electrochemiluminescence" 
in Analytical Electrogenerated Chemiluminescence: From Fundamentals to Bioassays, Eds. Sojic, N., The Royal Society of Chemistry, 200-246.

[71] Fiorani, A., Irkham, Valenti, G., Paolucci, F., and Einaga, Y., 2018, Electrogenerated chemiluminescence with peroxydisulfate as a coreactant using boron doped diamond electrodes, Anal. Chem., 90 (21), 12959-12963.

[72] $\mathrm{Hu}, \mathrm{L}$. , and $\mathrm{Xu}, \mathrm{G} ., 2010$, Applications and trends in electrochemiluminescence, Chem. Soc. Rev., 39 (8), 3275-3304.

[73] BioVeris Corporation, M-SERIES ${ }^{\circledast} 384$ Analyzer, https://www.selectscience.net/products/m-series-384analyzer/?prodid=20713\#tab-2, accessed on June 11, 2021.

[74] Shah, H.P., Hall, L.O., Powell, M.J., and Massey, R.J., 2005, Particle based electrochemiluminescent assays, US Patent No. 6881536B1, US Patent and Trademark Office, Washington DC, United States.

[75] Qin, J., 2014, Electrochemiluminescence immunoassay method, US Patent No. 20140072963A1, US Patent and Trademark Office, Washington DC, United States.

[76] Kumar, S.M., Otten, J.M., Davis, C.Q., and Biebuyck, H., 2003, Electrochemiluminescence flow cell and flow cell components, CA Patent No. 2493905A1, Canadian Intellectual Property Office (CIPO), Quebec, Canada.

[77] Li, Z., Yang, H., Sun, L., Qi, H., Gao, Q., and Zhang, C., 2015, Electrogenerated chemiluminescence biosensors for the detection of pathogenic bacteria using antimicrobial peptides as capture/signal probes, Sens. Actuators, B, 210, 468-474.

[78] Huang, Z.J., Han, W.D., Wu, Y.H., Hu, X.G., Yuan, Y.N., Chen, W., Peng, H.P., Liu, A.L., and Lin, X.H., 2017, Magnetic electrochemiluminescent immunoassay with quantum dots label for highly efficient detection of the tumor marker $\alpha$-fetoprotein, J. Electroanal. Chem., 785, 8-13.

[79] Wang, J., Guo, X., Li, H., Jin, Y., Chen, L., and Kang, Q., 2017, A signal-on electrochemiluminescence immunosensor for detecting alpha fetoprotein using gold nanoparticle-graphite-like carbon nitride nanocomposite as signal probe, Int. J. Electrochem. Sci., 12, 9784-9797.
[80] Fang, Q., Lin, Z., Lu, F., Chen, Y., Huang, X., and Gao, W., 2019, A sensitive electrochemiluminescence immunosensor for the detection of PSA based on CdWS nanocrystals and $\mathrm{Ag}^{+} @ \mathrm{UIO}-66-\mathrm{NH}_{2}$ as a novel coreaction accelerator, Electrochim. Acta, 302, 207-215.

[81] Rayavarapu, R.G., Petersen, W., Ungureanu, C., Post, J.N., van Leeuwen, T.G., and Manohar, S., 2007, Synthesis and bioconjugation of gold nanoparticles as potential molecular probes for light-based imaging techniques, Int. J. Biomed. Imaging, 2007, 029817.

[82] Wang, C., Zhu, W., Yan, T., Yang, L., Kuang, X., Du, B., Pang, X., and Wei, Q., 2018, Novel electrochemiluminescent platform based on gold nanoparticles functionalized $\mathrm{Ti}$ doped $\mathrm{BiOBr}$ for ultrasensitive immunosensing of NT-proBNP, Sens. Actuators, B, 277, 401-407.

[83] Shao, K., Wang, J., Jiang, X., Shao, F., Li, T., Ye, S., Chen, L., and Han, H., 2014, Stretch-stowagegrowth strategy to fabricate tunable triply-amplified electrochemiluminescence immunosensor for ultrasensitive detection of pseudorabies virus antibody, Anal. Chem., 86 (12), 5749-5757.

[84] Yang, H., Wang, Y., Qi, H., Gao, Q., and Zhang, C., 2012, Electrogenerated chemiluminescence biosensor incorporating ruthenium complexlabelled Concanavalin $\mathrm{A}$ as a probe for the detection of Escherichia coli, Biosens. Bioelectron., 35 (1), 376381.

[85] Lv, X., Li, Y., Yan, T., Pang, X., Hu, L., Du, B., and Wei, Q., 2015, An electrochemiluminescent immunosensor based on $\mathrm{CdS}-\mathrm{Fe}_{3} \mathrm{O}_{4}$ nanocomposite electrodes for the detection of Ochratoxin A, New J. Chem., 39 (6), 4259-4264.

[86] Wang, C., Jiang, T., Zhao, K., Deng, A., and Li, J., 2019, A novel electrochemiluminescent immunoassay for diclofenac using conductive polymer functionalized graphene oxide as labels and gold nanorods as signal enhancers, Talanta, 193, 184-191.

[87] Ai, Y., Li, X., Zhang, L., Zhong, W., and Wang, J., 2018, Highly sensitive electrochemiluminescent 
immunoassay for neuron-specific enolase amplified by single-walled carbon nanohorns and enzymatic biocatalytic precipitation, J. Electroanal. Chem., 818, 257-264.

[88] Dong, T., Hu, L., Zhao, K., Deng, A., and Li, J., 2016, Multiple signal amplified electrochemiluminescent immunoassay for brombuterol detection using gold nanoparticles and polyamidoamine dendrimerssilver nanoribbon, Anal. Chim. Acta, 945, 85-94.

[89] Wang, C., Hu, L., Zhao, K., Deng, A., and Li, J., 2018, Multiple signal amplification electrochemiluminescent immunoassay for Sudan I using gold nanorods functionalized graphene oxide and palladium/aurum core-shell nanocrystallines as labels, Electrochim. Acta, 278, 352-362.

[90] Liu, X., Fang, C., Yan, J., Li, H., and Tu, Y., 2018, A sensitive electrochemiluminescent biosensor based on AuNP-functionalized ITO for a label-free immunoassay of C-peptide, Bioelectrochemistry, 123, 211-218.

[91] Zhu, Q., Liu, H., Zhang, J., Wu, K., Deng, A., and Li, J., 2017, Ultrasensitive QDs based electrochemiluminescent immunosensor for detecting ractopamine using AuNPs and $\mathrm{Au}$ nanoparticles@PDDA-graphene as amplifier, Sensors Actuators, B Chem., 243, 121-129.

[92] Xu, G., Zhang, S., Zhang, Q., Gong, L., Dai, H., and Lin, Y., 2016, Magnetic functionalized electrospun nanofibers for magnetically controlled ultrasensitive label-free electrochemiluminescent immune detection of aflatoxin B1, Sens. Actuators, B, 222, 707-713.

[93] Zhao, Y., Li, L., Hu, L., Zhang, Y., Wu, D., Ma, H., and Wei, Q., 2019, An electrochemiluminescence immunosensor for the $\mathrm{N}$-terminal brain natriuretic peptide based on the high quenching ability of polydopamine, Microchim. Acta, 186 (9), 606.

[94] Tang, M., Zhou, Z., Shangguan, L., Zhao, F., and Liu,
S., 2018, Electrochemiluminescent detection of cardiac troponin I by using soybean peroxidase labeled-antibody as signal amplifier, Talanta, 180, 47-53.

[95] Zhang, J.J., Kang, T.F., Hao, Y.C., Lu, L.P., and Cheng, S.Y., 2015, Electrochemiluminescent immunosensor based on CdS quantum dots for ultrasensitive detection of microcystin-LR, Sens. Actuators, B, 214, 117-123.

[96] Zhang, X., Zhang, B., Miao, W., and Zou, G., 2016, Molecular-counting-free and electrochemilumi nescent single-molecule immunoassay with dualstabilizers-capped CdSe nanocrystals as labels, Anal. Chem., 88 (10), 5482-5488.

[97] Gao, H., Wen, L., Wu, Y., Yan, X., Li, J., Li, X., Fu, Z., and $\mathrm{Wu}$, G., 2018, Sensitive and facile electrochemiluminescent immunoassay for detecting genetically modified rapeseed based on novel carbon nanoparticles, J. Agric. Food Chem., 66 (20), 5247-5253.

[98] Zhang, Y., Li, L., Yang, H., Ding, Y.N., Su, M., Zhu, J., Yan, M., Yu, J., and Song, X., 2013, Gold-silver nanocomposite-functionalized graphene sensing platform for an electrochemiluminescent immunoassay of a tumor marker, RSC Adv., 3 (34), 14701-14709.

[99] Liao, N., Zhuo, Y., Chai, Y., Xiang, Y., Cao, Y., Yuan, R., and Han, J., 2012, Amplified electrochemiluminescent immunosensing using apoferritin-templated poly(ethylenimine) nanoparticles as co-reactant, Chem. Commun., 48 (61), 7610-7612.

[100] Sardesai, N., Pan, S., and Rusling, J., 2009, Electrochemiluminescent immunosensor for detection of protein cancer biomarkers using carbon nanotube forests and $\left[\mathrm{Ru}-(\mathrm{bpy})_{3}\right]^{2+}$-doped silica nanoparticles, Chem. Commun., 33, 4968-4970. 